\title{
Habitação e Gestão Ambiental em Áreas de Mananciais: o caso do Município de Santo André (SP)'
}

\section{Housing and Environmental Management in Water Source Areas: the case of Santo André (SP)}

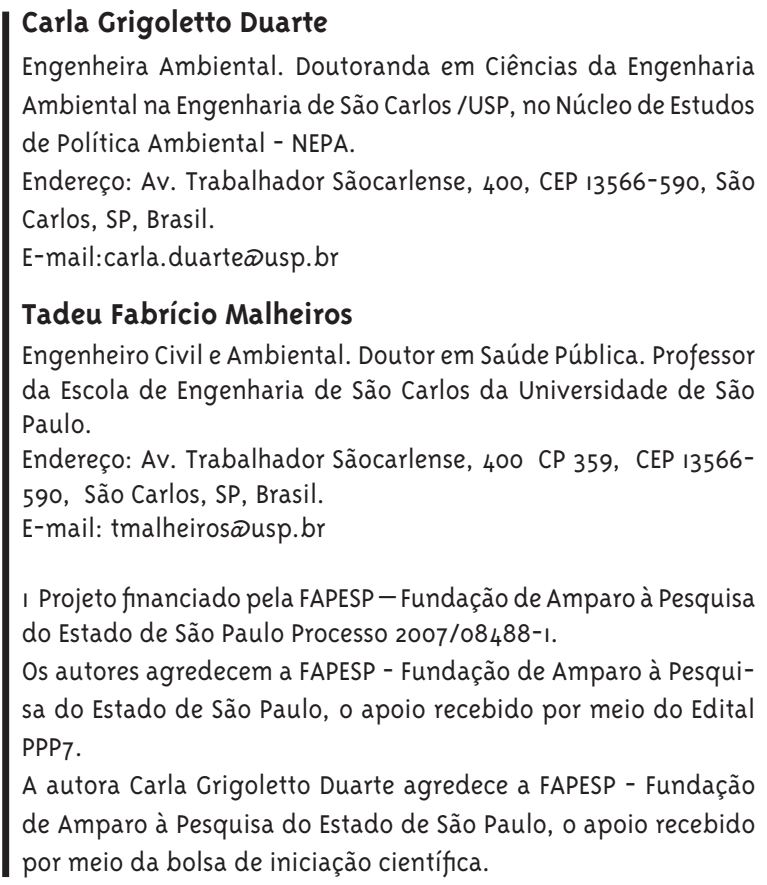

\section{Resumo}

Este artigo tem como objetivo levantar e discutir as ações de gestão ambiental e sua interface com a questão habitacional junto à área administrada pela Subprefeitura de Paranapiacaba e Parque Andreense, Santo André-SP, no biênio 2007-2008. O foco do trabalho é a capacidade política e institucional do município criada para tratar de tais questões. Os métodos usados foram pesquisa documental, bibliográfica e de campo, com entrevista a gestores do município. A pesquisa identificou que o município conta com propostas com grande potencial de contribuição para a melhoria da qualidade ambiental e habitacional na área de mananciais, principalmente por seu caráter de integração entre planejamentos. O estabelecimento de conselhos com participação de várias pastas representa um potencial elemento de integração nas ações desses órgãos, permitindo o compartilhamento de temas pertinentes ao longo do desenvolvimento das agendas de forma contínua. Quanto à recuperação urbana e ambiental dos loteamentos irregulares, é possível afirmar que os parâmetros urbanísticos e a definição do uso e ocupação do solo estão intimamente relacionados à qualidade ambiental e precisam ser construídos em conjunto por profissionais da área de urbanismo e da área ambiental, e discutidos com a comunidade local. O formato de gestão na área de mananciais, foco deste estudo de caso no município de Santo André, representa um significativo passo na construção da integração entre os sistemas de gerenciamento de recursos hídricos e de planejamento urbano/ metropolitano.

Palavras-chave: Meio Ambiente e Saúde Pública; Planejamento Ambiental; Habitação; Mananciais Protegidos; Políticas. 


\section{Abstract}

This article aims to survey and discuss environmental management actions and their interfaces with the housing issue in the area administered by the sub City Hall of Paranapiacaba and Parque Andreense, Santo André, SP. The focus is the political and institutional capacity established by the municipality to address such issues. The methods used were documental, literature and field research, with interviews with the municipality's managers. This research allowed to observe that the municipality has proposals with great potential to contribute to the improvement of the housing and environmental quality in the water source area, especially due to their character of integration in the planningphases. The establishment of multi-departmental councils is a potential element of integration in the actions of these organs, allowing a continuous sharing of relevant issues throughout the development of agendas. Concerning the environmental and urban regeneration of irregular settlements, it is clear that the urban parameters and the definition of land use are closely related to environmental quality and must be built jointly by professionals in urban planning and environmental area and discussed with the local community. The format of management in water source areas, the focus of this case study in the municipality of Santo André, represents a significant step to build integration between the water management system and urban/metropolitan planning.

Keywords: Environment and Public Health; Environmental Planning; Housing; Water Source Areas; Policies.

\section{Introdução}

A Região Metropolitana de São Paulo (RMSP) tem mais de 50\% de seu território localizado em área de mananciais. A exclusão social e a falta de políticas públicas eficazes culminaram em um aumento das ocupações irregulares nessas áreas, e por sua situação de ilegalidade frente à lei de proteção de mananciais o poder público ficou impedido de oferecer infraestrutura mínima de saneamento básico, configurando tais ocupações como fontes de poluição para os corpos d'água.

Há uma forte correlação entre saneamento, qualidade ambiental e saúde pública. Estudos epidemiológicos e a experiência de gestores na área de saneamento indicam que regiões carentes de investimentos em infraestruturas de serviços de esgotamento sanitário e coleta de resíduos sólidos ampliam os riscos de aparecimento de doenças de veiculação hídrica (Foratini, 1992; Philippi Jr e Malheiros, 2005).

Observa-se ainda uma estreita relação entre o uso do solo e qualidade ambiental no ambiente urbano, em especial quanto aos impactos causados em recursos hídricos por ocupações irregulares, o que ocorre em grande parte dos municípios brasileiros. Santo André é um dos municípios situados em área de mananciais da RMSP com ocupações irregulares, e vem atuando sobre este problema com políticas públicas diferenciadas. Este artigo tem como objetivo levantar e discutir as ações de gestão ambiental e sua interface com a questão habitacional junto à área administrada pela Subprefeitura de Paranapiacaba e Parque Andreense (SPPA), Santo André-SP. O foco do trabalho é a investigação da capacidade política e institucional criada para tratar de tais questões de interface.

Para alcançar o objetivo proposto foi realizada pesquisa bibliográfica, documental e de campo. O estudo de caso baseou-se na análise da Política Ambiental e da Política Urbana de Santo André, buscando relações existentes entre elas para a área delimitada neste estudo. Também foram consultados foram o Plano Diretor de Desenvolvimento Urbano do Município de Santo André ( 2004), dois volumes do Sumário de Dados de Santo André (2006 e 2008) e o Plano Municipal de Habitação (2006). Foram 
realizadas três entrevistas a gestores da SPPA para coleta de informações sobre as ações existentes e seu andamento, realizadas por meio de questões abertas. Os contatos foram feitos por meio da "Comissão Geral de Acompanhamento do projeto MEGA" (criada pela Portaria $n^{0}$ 607.07.2007 pelo então prefeito de Santo André), que indicou os responsáveis pelas temáticas de interesse.

Destaca-se também que estas atividades foram desenvolvidas no âmbito do projeto de pesquisa de iniciação científica "Ações Estratégicas de Gestão Ambiental em Áreas de Mananciais e suas Interfaces com a Habitação no Município de Santo André (SP)”, realizado no período de julho de 2007 a setembro de 2008, com apoio da FAPESP. Todas as atividades foram desenvolvidas também no contexto do projeto MEGA - "Avaliação Estratégica do Processo de Implementação das Políticas de Desenvolvimento e Meio Ambiente no Município de Santo André - SP”, com apoio da FAPESP na Linha de Pesquisa em Políticas Públicas.

\section{Gestão Pública, Gestão Ambiental e a Questão Habitacional}

Com a rapidez das mudanças sociais e tecnológicas, a gestão pública vem se tornando cada vez mais complexa e exige a reorganização do Estado para que seja capaz de enfrentar e dar respostas qualificadas aos desafios ambientais e sociais (Ibama, 2006).

No âmbito das discussões sobre desenvolvimento sustentável, um dos principais pontos abordados é a necessidade de inserção de questões ambientais e sociais nas agendas dos governos de forma mais efetiva. Para Dalal-Clayton e Bass (2002) os governos precisam adotar uma abordagem estratégica, com envolvimento de diversos atores e com o inter-relacionamento dos vários processos do desenvolvimento. Os autores afirmam que uma abordagem estratégica implica em: relacionar visões de longo prazo, metas de médio e ações de curto prazo; efetivar relações horizontais entre setores, de modo que haja uma abordagem coordenada para o desenvolvimento; fortalecer relações verticais, de modo a efetivar esforços e políticas em nível local, nacional e global, e que se complementem; e por fim, em estabelecer parcerias entre governo, empresas, comunidades e organizações voluntárias, uma vez que os problemas são complexos para serem resolvidos por qualquer grupo agindo isoladamente.

Essa abordagem implica em ampla integração entre planejamentos, o que exige novos formatos de gestão pública que privilegiem o diálogo entre instituições. As experiências nesse sentido ainda são recentes, principalmente na gestão municipal. Philippi Jr e colaboradores (2004) afirmam que um conjunto significativo de cidades enfrenta atualmente dificuldades sociais, econômicas e ambientais, em função principalmente do enfoque reducionista adotado na gestão de seu espaço. No caso brasileiro, alguns fatores podem ser identificados como agravantes da situação na gestão local, como a ausência de prioridade política para as questões ambientais e de saúde pública, o despreparo das equipes institucionais em lidar com questões complexas resultantes da dimensão socioambiental, as baixas receitas municipais e as cíclicas crises nacionais e mundiais.

A identificação e reconhecimento pelos atores locais desses pontos são importantes para o entendimento do processo de desenvolvimento do município, e de como estas dificuldades podem contribuir negativamente para a qualidade de vida da comunidade. Esses problemas comumente se repetem por várias gestões seguidas, gerando um círculo vicioso no qual se verifica insuficiência de recursos e ações de intervenção desencontradas, sem que esses problemas crônicos sejam superados (Philippi Jr e col., 2004).

No final dos anos 1980, o relatório Nosso Futuro Comum apresentado pela Comissão Brundtland apontou o desafio da gestão do espaço urbano considerando a dificuldade em oferecer infraestrutura no ritmo de crescimento das cidades em países em desenvolvimento, e a decadência da infraestrutura nos países industrializados. Para lidar com essa problemática, o relatório indicou a descentralização de recursos, de poder político e de pessoal na administração municipal (CMMAD, 1991).

Mendes e colaboradores (2004) avaliaram as experiências de quatro municípios na integração de agendas em projetos de melhoria da qualidade de vida, e afirmam que as propostas de integração setorial e participação pública de governos munici- 
pais implicam em mudar as tradicionais formas de gestão que estão histórica e culturalmente consolidadas. Também apontam que, para que uma nova cultura política seja criada, é preciso que "se definam novas formas de relação entre os diferentes níveis de governo e novas formas de cooperação e articulação no desenvolvimento de uma nova mentalidade, de novas habilidades e de estratégias para uma atuação conjunta e compartilhada" (Mendes e col., 2004, p. 54). Os autores concluem que a realização de planejamentos conjuntos e estratégicos é uma tarefa difícil de ser viabilizada, mas é possível dentro de uma perspectiva processual e gradativa.

Assim, uma das ações centrais para a inclusão das questões ambientais na gestão pública é a consolidação da gestão ambiental municipal, que deve ser feita de forma articulada com as questões sociais com as quais dialoga tão fortemente no recorte do município. Souza (200o, p. 11) afirma que a gestão ambiental pode ser entendida como "o conjunto de procedimentos que visam à conciliação entre desenvolvimento e qualidade ambiental”, e essa conciliação acontece a partir da observância da capacidade suporte do meio ambiente e das necessidades identificadas pela sociedade civil, pelo governo ou ainda por ambos. 0 mesmo autor afirma que a gestão ambiental encontra suas ferramentas de ação na legislação, na política ambiental e em seus instrumentos e também na participação da sociedade.

Como parte do Sistema Nacional de Meio Ambiente, SISNAMA, disposto na Política Nacional do Meio Ambiente, a gestão ambiental municipal deve se organizar por meio de um Sistema Municipal de Meio Ambiente. Milaré (1999, p. 34) define o Sistema Municipal de Meio Ambiente como o "conjunto de estrutura organizacional, diretrizes normativas e operacionais, implementação de ações gerenciais, relações institucionais e interação com a comunidade”. Os três principais integrantes do Sistema Municipal de Meio Ambiente devem ser: o Conselho Municipal de Meio Ambiente, como órgão superior do sistema, de caráter consultivo, normativo e deliberativo, responsável pela aprovação e acompanhamento da implementação da política municipal de meio ambiente; um órgão executivo municipal de meio ambiente, seja Secretaria, Diretoria ou Depar- tamento; e um fundo municipal de meio ambiente, para apoiar a captação e gerenciamento de recursos financeiros alocados para a área de meio ambiente (Ibama, 2006).

A partir de uma perspectiva estratégica que prioriza a integração entre planejamentos, o Sistema Municipal de Meio Ambiente deve estabelecer diálogo com as diversas políticas setoriais de desenvolvimento local, de forma a fortalecer e ampliar sua ação. E uma das principais questões a ser integrada em sistemas de meio ambiente no município é a habitação.

As normas gerais para habitação são definidas no contexto da política urbana. No Brasil, sua regulamentação se deu com a promulgação do Estatuto da Cidade, em 2001, com a Lei Federal nº 10.257. 0 Estatuto atribuiu aos municípios a função de implementar planos diretores participativos, definindo uma série de instrumentos urbanísticos que têm como objetivos principais o combate à especulação imobiliária e a regularização fundiária dos imóveis urbanos. O Estatuto da Cidade estabelece como objetivo da política urbana "ordenar o pleno desenvolvimento das funções sociais da cidade e da propriedade urbana", tendo como uma de suas diretrizes a garantia do direito a cidades sustentáveis, isto é, "o direito à terra urbana, à moradia, ao saneamento ambiental, à infraestrutura urbana, ao transporte e aos serviços públicos, ao trabalho e ao lazer, para as presentes e futuras gerações".

Os conceitos de habitação e moradia se tornam relevantes nesse contexto. Fernandes (2003) afirma que habitação adequada é também possuir qualidade ambiental que garanta a saúde pública, privacidade e espaço adequados, acessibilidade física, garantia de posse, estabilidade estrutural e durabilidade, iluminação adequada, aquecimento e ventilação, localização adequada e acessível em relação a trabalho; e tudo a um custo acessível. No mesmo sentido, é possível afirmar que uma moradia digna deve contar com o acesso às redes de infraestrutura - de transporte coletivo, abastecimento de água, coleta de esgotos, coleta de resíduos sólidos, fornecimento de energia elétrica, de iluminação pública, de telefonia, e pavimentação; bem como do acesso a serviços e equipamentos sociais básicos de educação, saúde, segurança, cultura e lazer. 
No entanto, os padrões de urbanização e de desenvolvimento das cidades da América Latina foram marcados pela precariedade de acesso à moradia digna enfrentada pelas populações carentes. 0 crescimento demográfico ocorrido principalmente no século XX foi desordenado, devido principalmente às migrações em busca da oferta de empregos gerada pela industrialização e posteriormente pelo setor de prestação de serviços (Bonotto, 2006). Tais migraçoes foram em grande parte feitas por populações carentes da área rural em contextos de mecanização agrícola que esvaziava postos de trabalho rurais e de poucas oportunidades de trabalho e emprego em núcleos urbanos menores . Em situação de pobreza, uma parte significativa desses migrantes ocupava regiões afastadas dos núcleos urbanos, criando novas configurações para o mercado imobiliário.

Esta conformação do espaço urbano está intimamente relacionada com a questão fundiária e com a lógica do mercado imobiliário. 0 mercado que se forma em torno da questão fundiária tem peculiaridades, já que o preço fundiário não é definido por resultado de trabalho, mas de uma demanda por terras, que suscita a oferta. A comercialização é feita a partir da fixação de preços, que, quando se trata do espaço urbano, se dá principalmente de acordo com a localização da terra (Bonotto, 2006).

Segundo Corrêa (1989, apud Sánchez, 2003), na formação de renda fundiária, a valorização das propriedades se dá devido à ocorrência de amenidades físicas, como a presença de áreas verdes, clima agradável, maior qualidade do ar, áreas distantes das atividades que afetam a paisagem e boas condições do terreno, e ainda amenidades socialmente produzidas, como serviços de infraestrutura e condições de acessibilidade. Dessa forma, as ocupações de baixa renda, incluindo os loteamentos irregulares e clandestinos, geralmente ocorrem em locais carentes de amenidades físicas ou socialmente produzidas.

A diferenciação dos preços fundiários tem papel fundamental na periferização da habitação, bem como na produção de vazios urbanos mantidos com fins especulativos. 0 mercado imobiliário adquire terrenos vazios e os estoca à espera de valorização futura. Os loteamentos novos são iniciados nas áreas mais distantes do espaço urbanizado, deixando intercaladas faixas de terras não loteadas. Os lotes são vendidos a preços baixos, atingindo o mercado popular e originando bairros de baixa renda que não dispõem dos serviços públicos essenciais. À medida que esses serviços vão sendo implementados, as faixas de terrenos estocados são valorizadas e são abertos novos loteamentos, mais caros (Spörl e Seabra, 1997).

Do ponto de vista ambiental, a implantação de loteamentos sem infraestrutura adequada causa impacto ambiental negativo, principalmente pelo despejo de efluentes domésticos e carreamento de resíduos sólidos, que reduzem a qualidade da água e ampliam os riscos, com consequente redução na qualidade de vida da população. Essa situação pode afetar, além da comunidade local, toda a população da bacia hidrográfica. A implantação de loteamentos pode causar a aceleração dos processos erosivos pela intensificação do escoamento das águas pluviais, diminuição da quantidade de água infiltrada no solo devido à impermeabilização do solo, supressão da vegetação de forma irreversível, degradação da vegetação pelo efeito de borda a fragmentos da vegetação e também incômodos à fauna que utiliza o local como passagem ou habitat (Freitas e col., 2001).

Assim, as interfaces da questão habitacional com a questão ambiental se inserem em um cenário de alta complexidade política e institucional, no direcionamento do mercado fundiário e imobiliário e também na integração setorial entre habitação e meio ambiente. Trata-se também de um cenário de alta complexidade técnica e tecnológica, pelo desafio de compatibilizar desenvolvimento urbano e limitações ambientais, provendo moradias dignas e proteção de recursos naturais.

Para lidar com problemáticas nesse contexto, certamente novos formatos de gestão pública com integração entre planejamento e com visão estratégica são fundamentais para aumentar a eficácia das políticas públicas.

\section{Contexto Histórico e Político: a área de mananciais e expansão urbana}

\section{na RMSP}

Para compreender o contexto da área de mananciais de Santo André, é importante retomar o histórico de ocupação dessa área e as políticas públicas implementadas para tratar da questão. 
O crescimento populacional vertiginoso na RMSP potencializou problemas já existentes, à medida que o novo contingente populacional demandou infraestrutura urbana e acesso a serviços públicos. A demanda habitacional para população de baixa renda atingiu níveis incompatíveis com as ofertas do mercado imobiliário da região metropolitana, o que resultou na ocorrência de ocupações irregulares ou clandestinas. Spörl e Seabra (1997) apontam que, na busca por um espaço, a população marginalizada encontrou três soluções para o problema da moradia: os cortiços, as favelas e a autoconstrução de habitações em loteamentos periféricos.

No caso da RMSP, as regiões periféricas estavam nas imediações dos mananciais de abastecimento de água. Os impactos negativos crescentes sobre a qualidade da água levaram sociedade e governo a elaborarem um conjunto de leis acerca dos mananciais no Estado de São Paulo ainda na década de 1970, que ficou conhecida como Legislação de Proteção aos Mananciais (LPM), baseada centralmente na definição de um zoneamento do uso do solo. A Lei Estadual no 898/75 definiu cerca de 50\% da área da RMSP como área de proteção aos mananciais (Figura 1).

\section{Figura I - Área de proteção aos mananciais na RMSP definida pela Lei Estadual $n$ 898/75}

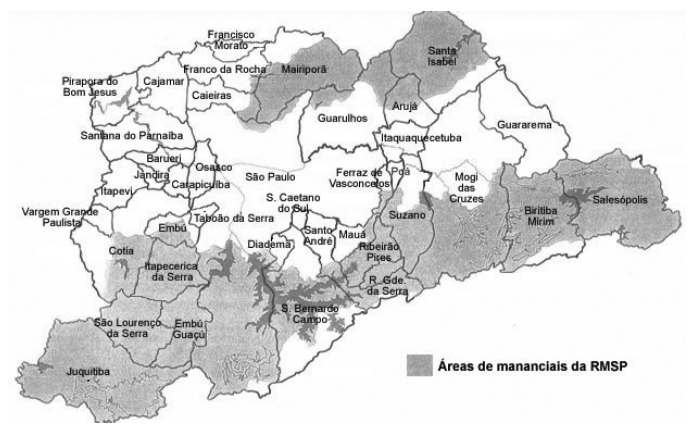

Fonte: SMA (2012)

De acordo com Silva e Porto (2003), a experiência pioneira da legislação de proteção a mananciais representou um passo fundamental na integração entre os sistemas de gerenciamento de recursos hídricos e de planejamento urbano metropolitano. O sistema de gerenciamento de recursos hídricos não era formalizado como hoje, mas havia articulações institucionais fundadas no aproveitamento múltiplo e na proteção dos recursos. Além disso, a concepção dos instrumentos propostos significava grande inovação, pois à época, as alternativas mais comuns para o administrador público envolvido com o abastecimento de água eram a desapropriação das áreas a serem protegidas ou a adoção de medidas estruturais, mediante tratamento avançado da água captada e ampliação da oferta a partir de mananciais distantes.

Entretanto, de acordo com Bruna e colaboradores (2004), as legislações da década de 1970 tiveram resultados contrários aos pretendidos pelos critérios definidos na legislação. Dentre as razões, destacam que as diversas restrições de ocupação do solo previam regiões com densidade muito baixa, dificultando a efetivação de empreendimentos, tanto de caráter industrial, quanto residencial, devido aos altos custos dos lotes; destacam também as limitações institucionais e a falta de agilidade dos procedimentos, que desestimulavam mesmo investidores em conformidade com a lei, já que havia a necessidade de se aprovar as atividades em diversos órgãos governamentais, resultando em processos longos e custosos.

Assim, ao estabelecer padrões rígidos de ocupação do solo, tais como a proibição de parcelamento e desdobramentos em lotes menores, o interesse de compradores sobre essas áreas diminuiu, desestimulando a atuação do mercado imobiliário formal (PMSA, 2006a). A incapacidade de atrair empreendimentos que pudessem permitir a sustentabilidade financeira dos municípios submetidos à legislação, somada à ineficiência da ação fiscalizadora, resultou na perda do controle estatal destas áreas atingidas.

Moroz e colaboradores (1994) argumentam que a LPM visava à proteção dos recursos hídricos, sem, no entanto, considerar o contexto histórico de expansão da metrópole. Ou seja, o fato de a LPM não ter sido articulada com uma política habitacional capaz de absorver a demanda na região foi um ponto frágil central para reduzir a efetividade da implementação dessa legislação. É preciso ressaltar ainda as limitações em termos de capacidade institucional e financeira existentes para que ocorresse a in- 
tegração necessária entre as políticas, que ainda contavam com a interferência de uma série de fortes interesses, muitas vezes conflitantes, de diferentes atores relacionados.

Buscando considerar as falhas na implementação da legislação da década de 1970, uma nova estratégia começou a ser elaborada na década de 1990, e resultou na nova lei de mananciais, Lei Estadual $n^{0} 9.866$ de 1997, que dispõe sobre normas e diretrizes para a proteção das bacias hidrográficas dos mananciais de interesse regional do Estado de São Paulo, e mudou a ótica sob a qual era tratada a questão.

A lei instituiu a gestão participativa por meio dos comitês de bacia, e descentralizou as ações por meio da criação de unidades de gerenciamento, denominadas Áreas de Proteção e Recuperação dos Mananciais (APRMs), formadas por uma ou mais sub-bacias, considerando características específicas da área definida. A partir de um cenário atual é estabelecido um cenário desejável de ocupação, e então são definidos o zoneamento ambiental, diretrizes de uso e ocupação, medidas de regularização, compensação, fiscalização, licenciamento, suporte financeiro e ações de monitoramento ambiental.

Cada APRM deve ser criada por uma lei específica, proposta pelos comitês de bacias hidrográficas. Essa lei deve estabelecer diretrizes de uso e ocupação do solo e normas ambientais e urbanísticas para cada uma destas áreas, considerando-se as peculiaridades e os processos de ocupação a que estão sujeitas. Dessa forma, a gestão de recursos hídricos estará atrelada à gestão do uso do solo do município.

Warner (2009) discute os avanços nas abordagens de gestão fluvial, mostrando que houve transição de uma visão focada em infraestruturas para controle das águas, para uma tentativa de afastar as populações humanas das zonas de risco por meio de zoneamentos. Posteriormente, houve uma tentativa de aliar essas duas visões incluindo a participação da sociedade civil. Essa trajetória é muito semelhante ao caso da RMSP, e essa nova abordagem de planejamento integrado tem trazido grandes desafios aos gestores, principalmente quanto aos conflitos no diálogo entre as partes interessadas.

\section{O Caso de Santo André}

O município de Santo André, localizado na Região Metropolitana de São Paulo, possui políticas públicas diferenciadas para a área de mananciais, com iniciativas para a gestão ambiental e habitacional. O município é apresentado por Whately e colaboradores (2008) como o mais preservado da bacia hidrográfica da Billings por suas áreas de remanescentes de Mata Atlântica.

Santo André possui área de $175 \mathrm{~km}^{2}$ e sua população estimada em 2010 foi de 673,9 mil habitantes (IBGE, 2010). O município possui $54,8 \%$ de seu território em área de mananciais (ISA, 2002), correspondente à Bacia da Billings, nas sub-bacias do Rio Grande e Rio Pequeno, definidas no Plano Diretor Municipal como Macrozona de Proteção Ambiental.

Um levantamento realizado pelo Ministério das Cidades publicado em 2007 mostrou que o número de domicílios em assentamentos precários em Santo André era percentualmente inferior aos números da RMSP, de 10,87\% para Santo André e 14,37\% para a RMSP (Marques e col., 2007). De acordo com dados da prefeitura municipal, esses assentamentos precários não estão concentrados nas áreas ambientalmente mais sensíveis do município - as áreas de mananciais (PMSA, 2006a).

Contudo, o crescimento populacional na área de mananciais na década de 1990 foi significativo, como mostra a Tabela 1. Em 2005, havia mais de 31 mil habitantes na área de mananciais, distribuídos em vinte loteamentos, na Vila de Paranapiacaba e em sete núcleos de assentamentos precários que surgiram na região. À época, o maior desses assentamentos era o Núcleo Pintassilgo, com cerca de 1.300 domicílios e 4.50o moradores (PMSA, 2006a).

A região foi, durante certo período, motivo de disputa judicial com os municípios de Ribeirão Pires e Rio Grande da Serra. O vácuo administrativo causado pela disputa judicial permitiu que vários loteamentos na área fossem aprovados por municípios vizinhos sem a anuência de Santo André, (PMSA, 2006b). O quadro 1 mostra características dos loteamentos da área de mananciais. Como pode ser observado, os lotes são em sua maioria de grandes dimensões, o que resulta em uma baixa densidade populacional na maioria dos loteamentos. 
Tabela I - Crescimento Populacional (\%) na área urbana e na Área de Proteção aos Mananciais de Santo André em 1991, 1996 e 2000

\begin{tabular}{lccccc} 
Área da cidade (Santo André) & \multicolumn{3}{c}{ População total } & Total no período & Total no período (\%) \\
& 1991 & 1996 & 2000 & & \\
Área urbana & 595.775 & 600.536 & 618.220 & 22.445 & 3,8 \\
Área de proteção aos mananciais & 17.583 & 24.373 & 31.111 & 13.528 & 76,9 \\
Total & 613.358 & 624.909 & 649.331 & 35.973 & 5,9 \\
\hline
\end{tabular}

Fonte: IBCE, Censos Demográficos - PSA, DISE apud PMSA (2006a).

Quadro I - Loteamentos existentes na área administrada pela Subprefeitura de Paranapiacaba e Parque Andreense em 2004

\begin{tabular}{|c|c|c|c|c|}
\hline N. & Loteamento & Data de aprovação & Município de aprovação & Tamanhos dos lotes $\left(\mathrm{m}^{2}\right)$ \\
\hline 1 & Acampamento Anchieta & Não consta & - & 770 a 72.600 \\
\hline 2 & Chácara Carreira & Não consta & - & 703 a 6.319 \\
\hline 3 & Chácaras Engenho da Serra & 1977 & Ribeirão Pires & 1.225 a 5.400 \\
\hline 4 & Estância Rio Grande & 1973 & Rio Grande da Serra & 1.381 a 15.440 \\
\hline 5 & Jardim Alteza & 1979 & Ribeirão Pires & 2.340 a 11.500 \\
\hline 6 & Jardim Clube de Campo & 1957 & Ribeirão Pires & 250 a 3.315 \\
\hline 7 & Jardim das Garças & 1971 & Santo André & 10.025 a 18.266 \\
\hline 8 & Jardim Guaripocaba & 1974 & Ribeirão Pires & 2.500 a 5.670 \\
\hline 9 & Jardim Joaquim Eugênio Lima & $1970^{*}$ & Rio Grande da Serra & $1.900 \mathrm{a} 80.700$ \\
\hline 10 & Jardim Silvia & Não consta & - & 910 a 4.184 \\
\hline 11 & Parque América & 1979 & Rio Grande da Serra & 739 a 4.640 \\
\hline 12 & Parque Billings & 1981 & Ribeirão Pires & 2.845 a 3.575 \\
\hline 13 & Parque das Garças & 1962 & Santo André & 1.875 a 16.450 \\
\hline 14 & Parque Represa Billings -2 & 1958 & Ribeirão Pires & 270 a 478 \\
\hline 15 & Parque Represa Billings -3 & 1955 & Ribeirão Pires & 253 a 635 \\
\hline 16 & Parque Rio Grande & 1960 & Ribeirão Pires & 1.456 a 29.750 \\
\hline 17 & Sítio São Benedicto & Não consta & - & 3.800 a 6.200 \\
\hline 18 & Sítio Taquaral & 1962 & Ribeirão Pires & $2.300 \mathrm{a} 10.000$ \\
\hline
\end{tabular}

* apenas arruamento Fonte: PMSA (2008). 
Figura 2 - Loteamentos na Área de Proteção e Recuperação de Mananciais Administrada pela SPPA - 2008.

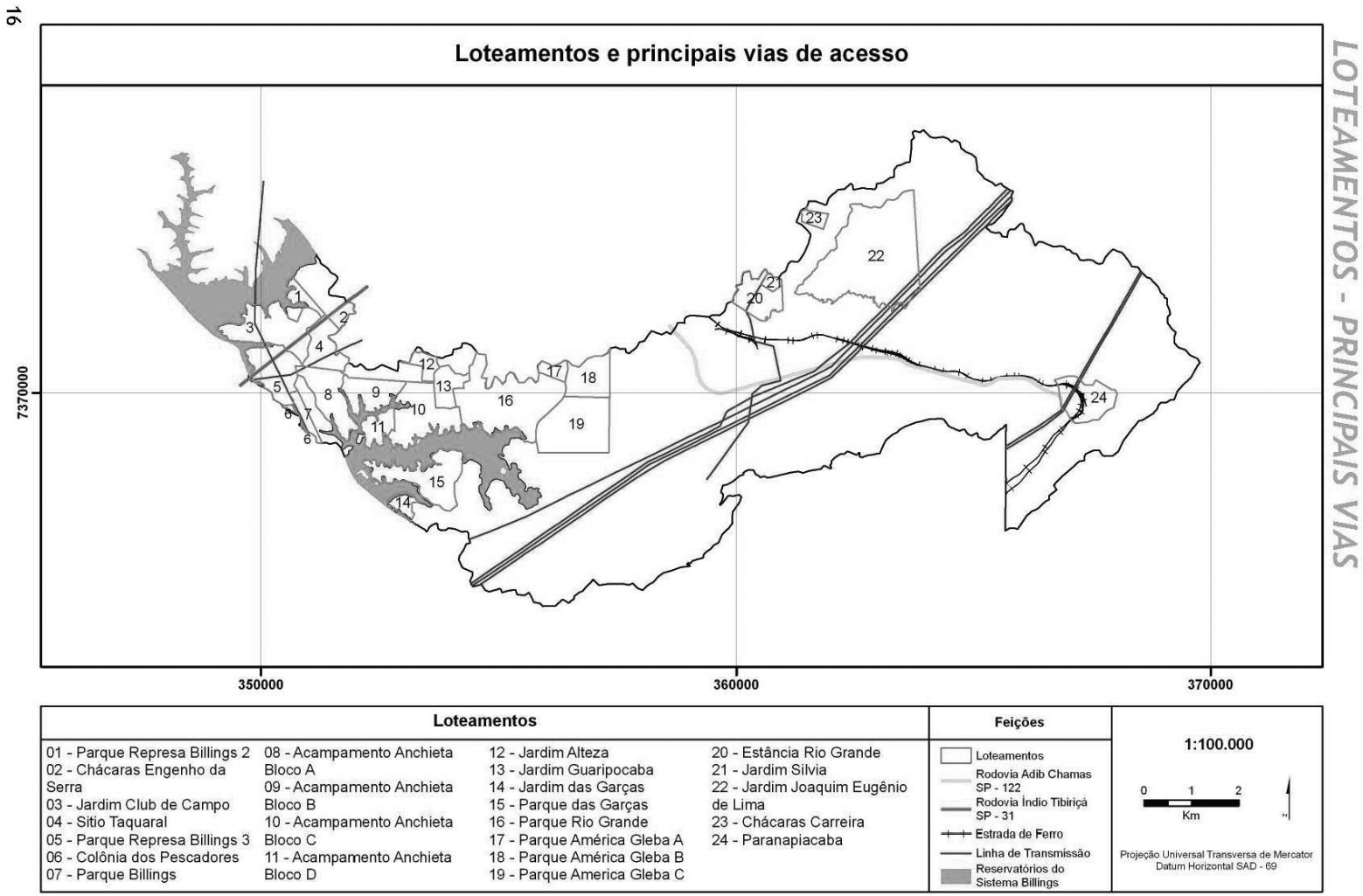

Fonte: PMSA (2008).

Embora os loteamentos tenham sido apenas parcialmente implantados e ocupados na área de mananciais de Santo André, todos eles apresentam, em maior ou menor escala, problemas quanto à sua regularização fundiária, desmembramentos, implantação e adaptação à legislação de proteção e recuperação dos mananciais vigente.

\section{Gestão Municipal na Área de Mananciais}

Para compreender as interfaces das políticas públicas relacionadas à habitação e meio ambiente na área de mananciais serão apresentadas três iniciativas: a criação da SPPA, a política ambiental e a política urbana.

De acordo com PMSA (2006b), a relevância e sensibilidade ambiental da área de mananciais levaram o governo municipal a buscar uma estra- tégia de gestão que pudesse centralizar todos os serviços municipais já existentes, incluindo saúde, educação, limpeza, manutenção geral, e ampliandoos com novos serviços de cultura, lazer, esportes, desenvolvimento econômico e segurança, inserindo a preocupação com a fragilidade ambiental da área na rotina de todos os serviços públicos. Dessa forma, buscou-se dar autonomia administrativa para a gestão da região com a centralização de todas as atribuições da prefeitura em um único organismo, criado em 2001, a Subprefeitura de Paranapiacaba e Parque Andreense (SPPA). A área administrada pela SPPA correspondia a $80,6 \%$ da área de mananciais do município, iniciando na divisa natural criada pelo braço do Rio Grande, como mostrado na Figura 2.

Para funcionar como um canal de diálogo com a sociedade civil foi criado em 2002 o Conselho de Representantes de Paranapiacaba e Parque An- 
dreense (CRPPA), como um espaço democrático de discussões, reflexões, encaminhamentos e definição de políticas públicas para a região administrada pela SPPA. O CRPPA tinha como membros catorze representantes titulares da população e catorze representantes titulares do governo formando um conjunto de vinte e oito conselheiros, com representantes do comércio, indústria, entidades e também de outros Conselhos Municipais como o de Orçamento, de Saúde, de Educação, de Transporte e também o Conselho Municipal de Gestão e Saneamento Ambiental.

Quanto à política ambiental municipal, as ações de gestão ambiental em Santo André estão estruturadas em torno da Política Municipal de Gestão e Saneamento Ambiental (PMGSA) - Lei Municipal $\mathrm{n}^{0} 7.733$ de 1998 , que por sua vez, institui o Sistema Municipal de Gestão e Saneamento Ambiental - SIMGESA, composto pelo Conselho Municipal de Gestão e Saneamento Ambiental (COMUGESAN) como órgão consultivo e deliberativo; pelo Serviço Municipal de Saneamento Ambiental de Santo André (SEMASA) como órgão técnico e executivo; e diversas secretarias municipais como órgãos colaboradores, e entre eles a Secretaria de Desenvolvimento Urbano e Habitação e a SPPA. Também foi criado o FUMGESAN - Fundo Municipal de Gestão e Saneamento
Ambiental de Santo André, para concentrar recursos para projetos de interesse ambiental.

o COMUGESAN é paritário e formado por trinta membros efetivos e seus suplentes ${ }^{2}$, sendo quinze representantes do Poder Executivo Municipal, escolhidos pelo Prefeito, e quinze representantes da sociedade civil.

Quanto à organização governamental em torno da questão habitacional, ela está fundamentada nas diretrizes dadas pela Política Urbana consolidada com o novo Plano Diretor Participativo, Lei Municipal nº 8.696 de 2004. A Política Urbana também é gerida por um órgão participativo - o Conselho Municipal de Política Urbana (CMPU), composto por: dezenove representantes do Governo Municipal, entre eles a Secretarias de Desenvolvimento Urbano e Habitação, o SEMASA e a SPPA; dezenove representantes da sociedade civil, entre os quais cinco representantes dos conselhos municipais afins - de Gestão e Saneamento Ambiental, Habitação, Transporte, Orçamento e Desenvolvimento Econômico.

Assim, os conselhos possuem representantes de outros conselhos, aumentando potencialmente a possibilidade de diálogo entre as diferentes agendas. A interação entre conselhos pode ser vista na Figura 3.

\section{Figura 3 - Participações integradas em habitação e meio ambiente nos conselhos CMPU, COMUGESAN e CRPPA em Santo André, SP}

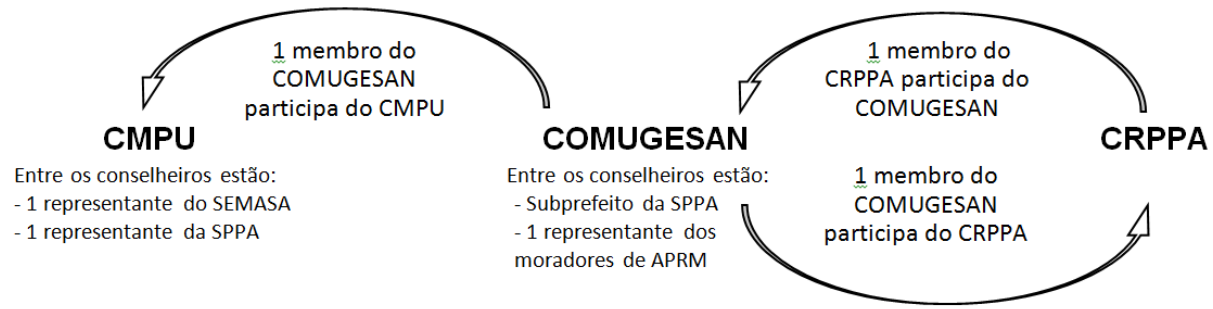

2 conforme texto e alteração da Lei Municipal nº. 8.676/o4 
declividade acentuada ou estão em Áreas de Preservação Permanente.

Com a Lei ${ }^{0}{ }^{0}$ 9.866/97 de proteção e recuperação dos mananciais, os parâmetros para a regularização fundiária passaram a depender da aprovação de uma lei específica. No caso de Santo André, foi a Lei Específica da Sub-bacia Hidrográfica BillingsTamanduateí, Lei Estadual nº 13.579 de 2009, que instituiu a Área de Proteção e Recuperação dos Mananciais da Bacia Hidrográfica do Reservatório Billings - APRM-B, definindo o zoneamento da região e seus parâmetros de ocupação (lote mínimo, taxa de permeabilidade e índice de área vegetada).

Ainda antes da lei específica, o primeiro loteamento que passou por processo de regularização fundiária foi o Parque América, que está nos territórios dos municípios de Santo André e Rio Grande da Serra. Devido a irregularidades em sua implantação houve o embargo judicial da área em 1994 e por mais de seis anos não ocorreram encaminhamentos judiciais que resultassem em solução ao problema. Em 2002, foi realizada uma audiência no Fórum de Santo André, em que uma equipe multidisciplinar de ambas as prefeituras elaborou uma proposta de readequação fundiária, ambiental e urbanística, objeto do acordo judicial firmado entre as Prefeituras e a empresa loteadora, em julho de 2005 (Santo André, 2008).

Atualmente, a SPPA está atuando no caso dos loteamentos Parque Represa Billings II e III. Em 2002, a Prefeitura moveu ação civil pública contra o loteador para a regularização da área. Também nesse caso foi iniciativa da Prefeitura elaborar a proposta de regularização e submetê-la à apreciação do Poder Judiciário. Após longo tempo foi possível manter negociações com o loteador sobre as mudanças pretendidas para o loteamento (Santo André, 2008). A proposta para o loteamento Parque Represa Billings III foi feita no contexto do projeto Gerenciamento Participativo de Áreas de Mananciais - GEPAM, em que um projeto urbanístico piloto foi implementado definindo pavimentação de vias, sistema de drena- gem urbano, tratamento de esgotos e uma área de lazer e paisagismo, e também a remoção de lotes sobre Áreas de Preservação Permanente (PMSA e CIDA, 2004).

O projeto GEPAM foi desenvolvido entre $1998 \mathrm{e}$ 2004 em parceira com a Agência Canadense para o Desenvolvimento Internacional - CIDA - e o Centro de Estudos sobre Assentamentos Humanos da Universidade de British Columbia e visou à melhoria da qualidade ambiental na área de mananciais de Santo André, por meio da redução dos danos ao meio ambiente causados por assentamentos humanos. Seu enfoque é o envolvimento comunitário no processo de desenvolvimento, e a melhoria da qualidade e disponibilidade das informações necessárias para o processo decisório municipal em relação ao gerenciamento nas áreas de mananciais. Além do Parque Represa Billings III, o projeto GEPAM atuou na reurbanização e recuperação de áreas no Núcleo Pintassilgo ${ }^{3}$ (CHS, 2010), e no Parque Andreense, que foram objeto de um Termo de Ajustamento de Conduta, conforme Lopes (2009).

\section{Discussões e Conclusão}

Santo André possui um sistema de gestão ambiental com significativos avanços, considerando a existência de uma Política Ambiental, órgão executivo, fundo de meio ambiente e ainda o conselho como canal de diálogo com outros órgãos e sociedade civil. O SIMGESA, enquanto estrutura político-administrativa, reúne as ações ambientais, fortalecendo e valorizando as principais questões da gestão ambiental urbana, e permite também avançar na inserção da temática ambiental nos processos decisórios municipais.

A composição dos conselhos dos Representantes de Paranapiacaba e Parque Andreense, de Política Urbana e de Gestão e Saneamento Ambiental representa um potencial elemento de integração nas ações desses órgãos, permitindo o compartilhamento de temas pertinentes ao longo do desenvolvi-

\footnotetext{
3 Informações sobre os projetos realizados podem ser encontradas em <http://www.semasa.sp.gov.br/admin/biblioteca/docs/pdf/livro3. pdf> para o Parque Represa Billings e <http://www.semasa.sp.gov.br/Documentos/Manancial/Mananciais.pdf> para o Núcleo Pintassilgo. Outras informações sobre os loteamentos podem ser encontradas nas páginas 76-82 de CEZARE, J.P. Conselhos Municipais e Governança Ambiental: uma análise do Conselho de Representantes de Paranapiacaba e Parque Andreense do município de Santo André. Dissertação (Mestrado). Faculdade de Saúde Pública, Universidade de São Paulo, 2009.
} 
mento das agendas, continuamente. No período da pesquisa, foi possível observar que a PMSA buscava realizar periodicamente atividades de integração e capacitação de seus colaboradores, e também de integrantes dos conselhos municipais, isso porque era de entendimento que a sensibilização e capacitação dos conselheiros deveriam ser processos contínuos, principalmente por conta da rotatividade inerente e necessária nestes colegiados (Duarte, 2008).

A compreensão das interfaces entre habitação e meio ambiente por parte dos conselheiros, técnicos e gestores será fundamental para o adequado direcionamento das ações do município, bem como as habilidades desses atores na superação de conflitos que surgirem nas pautas de negociação. Dessa forma, é possível afirmar que a capacitação técnica e política para a participação nos fóruns e também na elaboração de estudos ambientais e urbanísticos são fatores chave para a efetivação de ações de proteção dos mananciais. Nesse ponto, as contribuições do aprendizado no contexto do projeto GEPAM potencializam a elaboração de soluções técnicas de forma participativa para subsidiar as decisões quanto à regularização fundiária na região, aliando objetivos da agenda verde e da agenda marrom.

O reduzido número de assentamentos precários na região de estudo em relação a outros municípios da RMSP ressalta a importância da efetivação de políticas de proteção ambiental para que a qualidade ambiental nessa região seja mantida. Baltrusis e Ancona (2006) afirmam que é necessário continuar investindo em áreas periféricas como é o caso da área de mananciais, criando uma estrutura de oportunidades e condições para que o desenvolvimento destes assentamentos já consolidados ocorra de forma mais harmônica com as condições ambientais. Os projetos de recuperação urbana e regularização fundiária podem contemplar o aumento de infraestrutura e de equipamentos urbanos nas áreas, trazendo melhorias para a habitação e para o meio ambiente, bem como maior proteção da saúde pública da comunidade local e da população associada ao manancial.

A regularização fundiária apresenta-se como ação central na recuperação urbana e ambiental dos loteamentos irregulares da área. Os parâmetros urbanísticos e definição do uso e ocupação do solo estão intimamente relacionados à qualidade ambiental, e precisam ser construídos em conjunto por profissionais da área de urbanismo e da área ambiental, e com abertura para a comunidade local. As diversas visitas e reuniões realizadas pelo projeto MEGA junto às comunidades de Paranapiacaba e Parque Andreense reforçam esta questão, uma vez que para a comunidade a questão habitacional é muito mais concreta do que a questão ambiental. A comunidade local nem sempre reconhece os problemas ambientais existentes, nem os associa com a presença dos loteamentos, não percebendo que os impactos nos recursos hídricos são resultantes de ações antrópicas de modificação do espaço natural. Dessa forma, é possível concluir que enfrentar a problemática ambiental sem uma estratégia integrada com outros setores pode ser pouco efetivo e sofrer falta de apoio e credibilidade, à medida que colocar em conflito a questão ambiental e a questão habitacional.

A proposta da lei $n^{0}$ 9.866/97 representa um avanço na abordagem de planejamento regional, com a busca pela integração entre os sistemas de gerenciamento de recursos hídricos e de planejamento urbano em contexto metropolitano. 0 contexto em que essa nova legislação de mananciais está inserida é bastante diferente do contexto da antiga LPM, sem a rápida expansão demográfica e com um arcabouço jurídico mais elaborado para situações de irregularidades. A organização institucional, consolidação de planejamentos e agentes municipais se mostram favoráveis à efetivação da lei específica em Santo André. Cabe ressaltar que a questão demográfica é central no planejamento ambiental urbano, e com isso, por mais que as políticas sejam bem delineadas e que o planejamento e a gestão sejam eficazes, a capacidade suporte da bacia hidrográfica deve ser observada como limitante para as ações antrópicas. É preciso que o corpo técnico e população estejam atentos para identificar mudanças na qualidade ambiental que exijam maior restrição de parâmetros (Duarte, 2008).

A experiência de organização político-institucional de Santo André é uma alternativa para tratar de questões ambientais e habitacionais de forma mais integrada, valorizando a participação pública, e ainda aliando estratégias ao contexto regional da 
bacia hidrográfica. Para melhoria contínua desse sistema, será importante avaliar regularmente a qualidade dos processos decisórios e dos resultados alcançados, buscando evoluir para formatos cada vez mais efetivos e eficazes de gestão pública nesse município.

\section{Referências}

BALTRUSIS, N.; ANCONA, A. L. Recuperação ambiental e saúde pública: o programa Guarapiranga. Saúde e Sociedade, São Paulo, v. 15, n. 1, p. 9-21, abr. 2006.

BONOTTO, C. D. de L. A concretização do direito constitucional à moradia a partir da implementação de políticas públicas de inclusão social. 2006. Dissertação (Mestrado em Direito) Universidade de Santa Cruz do Sul, Santa Cruz do Sul, RS.

BRUNA, G. B. et al. Análise crítica da legislação de proteção dos mananciais na Região Metropolitana de São Paulo. In: Seminário Internacional NUTAU 2004, São Paulo. Resumos... São Paulo: FAU, 2004. v.1.

SMA - Secretaria de Estado do Meio Ambiente. Área de Mananciais da Região Metropolitana de São Paulo. Il, color, 2012. Disponível em < http://sigam.ambiente.sp.gov.br/Sigam2/ Repositorio/196/Figuras/mapa_mananciais_o2. jpg>. Acesso em: 25 out. 2012.

CHS - The Centre for Human Settlements. Community-based watershed management in Santo André, São Paulo, Brazil - 1998-2004. Final Report. jan. 2005. Disponível em: <www.chs.ubc. $\mathrm{ca} /$ brazil>. Acesso em: 20 nov. 2010.

CMMAD - Comissão Mundial sobre Meio Ambiente e Desenvolvimento. Nosso Futuro Comum. Rio de Janeiro: FGV, 1991.

DALAL-CLAYTON, B; BASS, S. Sustainable development strategies: a resource book. London: Earthscan Publications, 2002.
DUARTE, C.G. Ações estratégicas de gestão ambiental em áreas de mananciais e suas interfaces com a habitação no município de Santo André (SP). 2008. Monografia (Graduação em Engenharia Ambiental) - Escola de Engenharia de São Carlos, Universidade de São Paulo, São Carlos, SP.

FORATINI, O.P. Ecologia, epidemiologia e sociedade. São Paulo: Artes Médicas/Edusp, 1992.

FERNANDES, M. Agenda habitat para municípios. Rio de Janeiro: IBAM, 2003. Disponível em: <http://www.empreende.org.br/pdf/Programas\%20 e\%2oPol\%C3\%ADticas\%2oSociais/Agenda\%2O Habitat\%2opara\%2oMunic\%C3\%ADpios.pdf >. Acesso em: 20 fev. 2010.

IBAMA - Instituto Brasileiro de Meio Ambiente e dos Recursos Naturais Renováveis. Programa Nacional de Capacitação de Gestores Ambientais. Brasília: Ibama, 20o6. (Cadernos de Formação. v. 1: Política Nacional do Meio Ambiente).

IBGE - Instituto Brasileiro de Geografia e Estatística. IBGE Cidades. Disponível em <http:// www.ibge.gov.br/cidadesat/topwindow.htm?1>.

Acesso em: 27 dez. 2010.

FREITAS, C. G. L. et al (Org.) Habitação e meio ambiente: abordagem integrada em empreendimentos de interesse social. São Paulo: Instituto de Pesquisas Tecnológicas do Estado de São Paulo, 2001.

ISA - Instituto Socioambiental. Billings 20oo: ameaças e perspectivas para o maior reservatório de água da Região Metropolitana de São Paulo. São Paulo: ISA, 2002.

LOPES, R. C. A. Ação civil pública e ajustamento de conduta em áreas de proteção aos mananciais na região metropolitana de São Paulo. 2009.

Dissertação (Mestrado em Arquitetura e Urbanismo) - Faculdade de Arquitetura e Urbanismo, Universidade de São Paulo, São Paulo.

MARQUES, E. (Coord.). Assentamentos precários no Brasil urbano. Brasília: Centro de Estudos da Metrópole, Secretaria Nacional de Habitação, Ministério das Cidades, 2007. 
MENDES, R.; BOGUS, C. M.; AKERMAN, M.

Agendas urbanas intersetoriais em quatro cidades de São Paulo. Saúde e Sociedade, São Paulo, v. 13, n. 1, p. 47-55, abr. 2004.

MILARÉ, É. Instrumentos legais e econômicos aplicáveis aos municípios. Sistema Municipal de Meio Ambiente - SISMUMA/SISNAMA. In: PHILIPPI JR., A. et al. Municípios e meio ambiente: perspectivas para a municipalização da gestão ambiental no Brasil. São Paulo: ANAMMA, 1999. p. 33-46.

MOROZ, I. C.; CANIL, K.; ROSS, J. Problemas ambientais na área de proteção aos mananciais da Região Metropolitana de São Paulo.. Revista do Departamento de Geografia, São Paulo, n. 7, 1994. p. $35-48$.

PHILIPPI JR, A. et al. Gestão ambiental municipal: subsídios para estruturação de sistema municipal de meio ambiente. Salvador: CRA, 2004. (Série Construindo os Recursos do Amanhã. v. 4).

PHILIPPI JR, A.; MALHEIROS, T. F. Saneamento e saúde pública: integrando homem e ambiente. In: PHILIPPI JR, A. (Ed.). Saneamento, saúde e ambiente: fundamentos para um desenvolvimento sustentável. Barueri: Manole, 2005. p. 3-31.

PMSA - Prefeitura Municipal de Santo André. Plano municipal de habitação. Santo André, 20o6a.

PMSA - Prefeitura Municipal de Santo André. Sumário de dados de Paranapiacaba e ParqueAndreense 2006 - ano-base: 2005. Santo André, 2006b.

PMSA - Prefeitura Municipal de Santo André. Sumário de dados de Paranapiacaba e Parque Andreense 2008 - ano-base: 2006 e 2007. Santo André, 2008. Disponível em: <http://www2. santoandre.sp.gov.br/page/173/49>. Acesso em: o6 jan. 2011.
PMSA - Prefeitura Municipal de Santo André. CIDA - Agência Canadense para o Desenvolvimento Internacional. Áreas ambientalmente sensíveis e regularização fundiária. In: BOOTHROYD, P. (Coord.). Projeto GEPAM. São Paulo: Annablume, 2004 .

SÁNCHEZ, P. S. O processo de ocupação em áreas de proteção aos mananciais: conflito com a lei e realidade social na Região Metropolitana de São Paulo: o caso de dois loteamentos ilegais no município de Mairiporã. 2003. Dissertação (Mestrado em Ciências da Engenharia Ambiental). Escola de Engenharia de São Carlos da Universidade de São Paulo, São Carlos.

SANTO ANDRÉ. Regularização fundiária nas áreas de proteção aos mananciais de Santo André. Santo André: Prefeitura Municipal de Santo André, 2008.

SILVA, R.T.; PORTO, M.F. do A. Gestão urbana e gestão das águas: caminhos da integração. Revista Estudos Avançados, São Paulo, v. 17, n. 47, p. 129-145, 2003.

SOUZA, M. P. Instrumentos de gestão ambiental: fundamentos e prática. Editora Riani Costa: São Carlos, 2000.

SPÖRL, A.; SEABRA, O.C.L. A lei de proteção aos mananciais versus a prática social de ocupação na Bacia do Guarapiranga. Revista do Departamento de Geografia, São Paulo, n. 11, p.113-129, 1997.

WARNER, J. A abordagem de planejamento conjunto para o planejamento hídrico: descobrindo um equilíbrio entre três paradigmas de governança. In: JACOBI, P. R.; SINISGALI, P. de A. (Org.). Dimensões político institucionais da governança da água na América Latina e Europa. São Paulo: Annablume, 2009. p.103-126. (Coleção Cidadania e Meio Ambiente).

WHATELY, M.; SANTORO, P. F.; TAGNIN, T. A. Contribuições para a elaboração de leis específicas de mananciais: o exemplo da Billings. São Paulo: Instituto Socioambiental, 2008. 